\title{
Los pótos según los malecus: identidad y aliciente moral, desde una visión estereotipada
}

\author{
The potoes according to the malecu people: identity and moral incentive, from a stereotyped point of \\ view
}

\section{Andrés Solano-Fallas ${ }^{1}$}

Fecha de recepción: 6-3-20

Fecha de aprobación: 8-3-21

\begin{abstract}
Resumen
El artículo tiene por objetivo dilucidar cómo la figura de los indígenas pótos, según su versión estereotipada en las pláticas malecus, contribuyó a la conformación de la identidad del endogrupo, y a su vez, fungió como aliciente moral. En lo que respecta a la configuración de la identidad, se exponen cinco estereotipos clave (de belleza, de intelectualidad, emocional, sobre conducta laboriosa, y sobre conducta sexual) que los malecus concibieron de los pótos, en orden a explicar cómo estos presuponen la imagen que el endogrupo tenía de sí. En cuanto al aliciente moral, se desarrolla cómo la visión sobre los pótos, implicó el rechazo de ciertas prácticas consideradas negativas que un malecu no debería ejercer, como también el reconocimiento de otras a seguir.
\end{abstract}

Palabras clave: malecus, pótos (póto maráma), estereotipos, identidad, aliciente moral

\begin{abstract}
The aim of this paper is to elucidate how the figure of indigenous pótoes, according to their stereotyped account in the malecu narrative, contributed to the conformation of the in-group's identity, and at the same time, it worked as moral incentive. Regarding to the identity configuration, it's exposed five key stereotypes (on beauty, on intellectuality, on emotions, about laborious conduct, and sexual conduct) that the malecu conceived about the pótoes, in order to explain how these presuppose the image that the in-group had on themselves. As to the moral incentive, it develops how the visualization about the pótoes, implied the rejection of some practices considered negative that a malecu should not perform, as well as the acknowledgement to follow others.
\end{abstract}

Key words: malecu (people), pótoes (póto maráma), stereotypes, identity, moral incentive

\footnotetext{
1 Magíster en Filosofía. Docente en la Universidad de Costa Rica, Sede del Pacífico y Escuela de Estudios Generales, Costa Rica. Tutor en la Universidad Estatal a Distancia, Costa Rica. Cátedra Filosofía de la Educación. Correo electrónico: sadsunsea@gmail.com
} 


\section{Introducción}

Los malecu(s), cuyo nombre significa "nuestra gente" (ma-, nuestro/a; lecu, gente/persona), es un pueblo indo-costarricense, perteneciente a la familia chibcha. Actualmente se encuentran en el norte del país, en el distrito de San Rafael, del cantón de Guatuso, de la provincia de Alajuela, en lo que ellos mismos denominan "Territorio Malecu", o bien, "Reserva Indígena de los Guatusos", de acuerdo a la oficialidad estatal costarricense, según su creación en 1976. A mediados del siglo XIX, su antiguo territorio posiblemente alcanzó 110000 hectáreas (110o Km cuadrados) ${ }^{2}$, coincidiendo en gran parte con el área de la cuenca del Río Frío; en el cual había por lo menos 17 palenques ${ }^{3}$, con una población que posiblemente rondaba entre las 1500 a 2000 personas (Castillo, 2005a y 2005b). No obstante, múltiples situaciones -como el sometimiento a esclavitud y casi-exterminio por parte de los huleros nicaragüenses (1868-19oo); y las posteriores migraciones internas a la zona, entre otras- provocó la drástica pérdida de tierras.

Cuando se crea la "Reserva", fue con un área de 2994 hectáreas (29.94 Km cuadrados), empero, en 1977, mediante decreto ejecutivo, se reduce la extensión a 2743 hectáreas (27.43 Km cuadrados) (Guevara-Víquez, 2011). Aunque este sea el área total del territorio, solamente 600 hectáreas (6 Km cuadrados) es "aproximadamente lo que está en control de la población indígena” (GuevaraVíquez, 2011, p. 24). Asimismo, de los varios palenques que existieron, en el presente hay tres: El Sol, Margarita y Tonjibe. En lo concerniente a la población, de acuerdo al Censo 2011 (INEC, 2013), es cercana a las 500 personas; de las cuales casi todas viven en el Territorio Malecu, junto con unas 900 personas no-indígenas. Conservan su idioma, aunque no toda la población es bilingüe; además, existen variantes entre cada palenque. No obstante, se halla en un estado de decrecimiento, ya que "se encuentran adultos con una competencia únicamente receptiva en malecu o con una competencia activa reducida, niños y jóvenes con diferentes grados de competencia pasiva y productiva y ya no sobreviven sujetos monolingües en malecu" (Sánchez-Avendaño, 2011, p. 88). ${ }^{4}$

Apuntado lo anterior, en este artículo se explica cómo la identidad del malecu antiguo ${ }^{5}$ se conformaba a partir de la visión estereotipada que tenía de su coetáneo indígena, el póto ${ }^{6}$, y a su vez, como dicha visión le servía como aliciente moral. Para ello se ha seleccionado como obra principal las "Pláticas de botos" (en Constenla-Umaña

2 Sobre este dato, deseo rectificar un error humano cometido en Solano-Fallas (2019 p.40; y 2018: p.3). Después de indicar las 2994 hectáreas del Territorio Malecu, reconocidas por parte del Estado costarricense, procedí a apuntar que el territorio histórico fue mucho más extenso, ya que alcanzaba las 1100 hectáreas. Claramente puede apreciarse el error, por cuanto que la segunda cifra es menor a la primera. En vez de "110o hectáreas", debe leerse correctamente "1100oo hectáreas".

3 El término "palenque" remite a un asentamiento multifamiliar, usualmente ubicado en la margen de algún río. Estos palenques estaban conformados por cuatro o cinco casas-ranchos grandes, a pocos metros de distancia entre cada una. En cada casa-rancho, "vivía una familia extendida compuesta por cuatro o cinco familias nucleares, cuyos miembros estaban emparentados entre sí por lazos de parentesco o matrimonio, y que en conjunto podían sumar unas 30 personas. De esta forma la población de un palenque podía oscilar entre los 90 y 120 habitantes" (Castillo, 2005a, p.80). Cada casa-rancho estaba construida sobre un plano rectangular o cuadrado, con un techo de dos vertientes, hecho de hojas de palma, y sin paredes (Castillo, 2005a, p. 80; Guevara-Berger y Chacón-Castro, 1992, p. 104). Hoy día, el término se utiliza de manera general para referirse a las comunidades que actualmente existen en el Territorio Malecu, debido a que los lugares habitacionales dejaron de ser ranchos. En el presente son casas unifamiliares, pequeñas, de concreto o madera, y techo de zinc, a raíz de una política de vivienda del Estado costarricense a partir de 1963 (Guevara-Berger y Chacón-Castro, 1992, p. 104).

4 El párrafo anterior y el presente, junto a las notas aclaratorias que contienen, están tomados íntegramente de Solano-Fallas (2019b), por cuanto que la finalidad es meramente informativa: presentar y aclarar al público que no está familiarizado con este pueblo indígena, quienes eran los malecus, y cuál fue el devenir de su territorio. Por ello, no considero necesario tener que reescribir lo anterior, ya que en esos dos párrafos se sintetiza la información necesaria para tener una noción de los malecus.

5 Sobre la diferenciación de "antigüedad” y “actualidad” de la cultura malecu, verse la Nota \#1 en Solano-Fallas (2018, p.19-20). Para un estudio más detallado, remitirse a Sánchez-Avendaño (2015).

6 A este grupo indígena se le denomina en español como "bóto" o "vóto", dado a que así se les conoció a partir de la Colonia (ConstenlaUmaña, 2014, p.10). En malecu, el término para este exogrupo es "póto” (en singular; y "póto maráma” en plural). Se ha preferido mantener el vocablo en malecu, con su debida castellanización cuando se le plurifica, aunque a veces se alterna con la traducción malecu. 
e Ibarra-Rojas, 2014) que consisten en una serie de 8 textos que narran cómo eran concebidos los pótos (póto maráma), algunos de los cuales muestran encuentros (sexuales o agresivos) entre ambos grupos. De manera secundaria se toma en consideración las descripciones del póto presentes en Pláticas sobre ogros (ConstenlaUmaña, 2014), que si bien los ogros tendían a victimizar con preferencia a los pótos, tales prácticas no ahondan demasiado en caracterizar demasiado a este grupo indígena, sino que presuponen su concepción? 7 . Ambas series de textos, valga señalar, tiene como marca indeleble estereotipos fuertemente arraigados en su imaginario, lo que sin duda presenta una versión distorsionada de los póto maráma, pero que contribuyeron a la configuración de la identidad malecu, dado que "los estereotipos cubren una amplia zona de las creencias sociales y tienen una función de primer orden en la construcción de la identidad social” (González-Gabaldón, 1999, p.79).

El artículo se compone básicamente de dos partes que remiten a cada tema: la identidad y el aliciente moral. En cuanto al primero, se inicia explicando cómo era concebido el póto, centrándose en por lo menos cinco grandes estereotipos presentes en los textos, a saber, estereotipo de belleza, estereotipo intelectual, estereotipo emocional, estereotipo sobre conducta laboriosa y estereotipo sexual. Acto seguido, se desarrolla cómo a partir de estos cinco estereotipos el malecu antiguo se concebía a sí mismo, dado que la figura del póto reúne aquellos rasgos que el malecu rechazaba o simplemente no se identificaba. En la medida que se realice esto, se muestran otras características que resultan ser propias de los malecus, pero trataron de obviar o negar mediante la visión peyorativa de los pótos. Respecto al segundo tema, se procede a explicar cómo la caracterización del póto implica una serie de estímulos morales, cuya finalidad consiste en que el malecu desestima algunos comportamientos considerados impropios -aunque como se expone, en algunos casos eran recurrentes a realizarlos-, pero también se le reconoce conductas que deberían ser seguidas por el endogrupo en cuestión -si bien, algunas no eran ejercidas-.

Sobre la citación, se opta por seguir la manera en que Constenla-Umaña los editó, en vez de utilizar APA, debido a que permite ubicar los pasajes fácil y puntualmente. En "Pláticas de bótos" los textos I, II, III, V, parcialmente el VII, y el VIII están enumerados con números romanos, y las líneas con números arábigos. Por ejemplo, VIII, 10-11, remite al texto número ocho, líneas 10 a la 11. No obstante, debido al deterioro de salud de Constenla-Umaña -quien finalmente falleció-, este le encargó la publicación a Ibarra-Rojas, pero sin finalizar la numeración arábiga en los siguientes textos: IV, VI y parcialmente el VII, por lo que no cuentan con líneas numeradas. Para paliar esta situación, se recurrió en estos textos señalar el número romano del texto en cuestión, y de la página en la que aparece la línea que se desea citar o referir. Por ejemplo, VI, p.143. A excepción de este lamentable inconveniente, cualquier otra serie de textos malecus que se refiera en este artículo si cuenta con la citación de números romanos y arábigos.

\section{Contexto narrativo e histórico de las pláticas}

Brevemente, los póto maráma eran seres pequeños, de los cuales se decían que no crecían mucho (I, 72; II, 13; VI, p.143; VII, p.147), que incluso se podían confundir con duendes por su baja estatura (I, 72). Según las pláticas, fueron creados en la primera creación por Cabecera del río Nharíne, por lo que eran congéneres de los malecus,

$7 \quad$ Si bien estos son los "textos base de trabajo" para el artículo, debe apuntarse que en orden a comprender tanto el contexto de las tramas narrativas contenidas en los dos ciclos narrativos indicados, como también el universo malecu en general, se requiere del apoyo de otras narraciones que le son vinculantes: Constenla-Umaña 1992, 1993, 1996, 2011a; Galante-Marcos, sin año, A; J.E.P Margarita-IETSAY 20oo; y Mejía-Marín 1994. 
y estos los consideraban humanos, aunque deficientes ${ }^{8}$. De acuerdo a Ibarra-Rojas (en Constenla-Umaña e IbarraRojas, 2014, p.114), en el siglo XVI los pótos vivían en las tierras más cercanas al Lago de Nicaragua y al río San Juan, pasando por el río Frío y llegando a pasar el río Sarapiquí. Según Constenla-Umaña (2014, p.135; nota \#2), en el recuerdo del endogrupo, como se transluce en las pláticas, los malecus parecen acordarse de ellos como vecinos específicamente de la zona circundante al curso inferior del río Frío, dado que ese era el lugar a donde fueron a dar los ogros, cuando estos fueron primeramente exiliados por Nharíne del territorio malecu, el cual se encontraba entre el curso superior y medio del río Frío. Debido a que Nharíne reubicó a los ogros en territorio póto, estos se convirtieron en sus víctimas preferenciales, por lo que este Dios tomó la decisión de exiliarlos finalmente de ahí. Finalmente, gracias al relativo buen comportamiento de los pótos, Nharíne hizo que tuvieran una buena muerte, antes de enviar el cataclismo que destruyó a la primera humanidad, por el mal comportamiento de los malecus. En la segunda creación, los póto maráma no volvieron a ser creados ${ }^{9}$.

\section{Configurador de identidad1o}

El grupo indígena de los póto maráma, según están representados por los dos ciclos de pláticas, tenía la función social de ser un medio por el cual los malecus

8 El ciclo cosmogónico que narra tanto la venida de los Dioses (tocú maráma) al mundo, sus dos creaciones, y otras peripecias, tales como la obtención del fuego, y el odio a la humanidad por parte de la Diosa que habita en la Cabecera del río Aóre, se encuentran en Laca Majifijica (Transformación de la Tierra), editada por Constenla-Umaña (1993). Debido a que dicha obra no se ha vuelto a publicar, lo que implica que sea de difícil acceso, puede remitirse a Solano-Fallas (2016) para ver una reseña sobre los aspectos cosmológicamente relevantes.

En cuanto a los nombres de los Dioses que aparecen en las distintas pláticas, como a los que se utilizan en este artículo, cabe comentar que no revelan el verdadero nombre de la divinidad, sino el lugar en el que moran, dado que no estaba permitido mencionar sus nombres reales. Por ejemplo, el Dios principal vive en la Cabecera de río Nharíne, pero por abreviación se referirá a este, y cualquier otro Dios/a, solamente por el nombre del río en malecu.

Valga señalar que Nharíne fue el encargado de crear casi todo: en la primera vez, fue por votación unánime, ya que los demás Dioses decidieron que el primero que había llegado al mundo se encargase de tal labor; en la segunda vez, fue él otra vez, porque su excompañera sentimental y madre de su hija, la Diosa Aóre, le había instigado a que destruyese la humanidad, a lo cual Nharíne había finalmente aceptado, siempre y cuando, ella crease todo, pero no pudo, por lo que él tuvo que asumir la labor.

9 Casi todos los textos coinciden en que no fueron creados nuevamente después del gran cataclismo, sin embargo, existen unos textos que indican lo contrario. En la nota \#18 del presente artículo, abordo este punto.

10 El tema de la identidad es un asunto complejo y de amplia discusión en el ámbito académico. A pesar de que existen varias posturas, tiende a moverse por lo menos entre dos grandes enfoques, el esencialista y el constructivista, cayendo a veces en un dualismo académico. En líneas muy generales, en el primer enfoque hay variantes en que las identidades "aparecen como un mero reflejo de un listado de rasgos culturales objetivos compartidos, desde otras aparecen como una expectativa que busca explicar lo que la gente hace o debiera hacer en base a quienes son o a qué cultura pertenecen” (Briones, citada en Quintana-Monge, 2016, p. 47). En otras palabras, no se toma en consideración el efecto o influencia, o causalidad de otras acciones y eventos, e incluso la propia voluntariedad del ser humano, conduciendo a la impresión de que hay cierta naturalidad e inmutabilidad en el contenido de la auto-denominación.

Por su parte, el segundo enfoque si toma en cuenta efectos, influencias, la voluntad de la persona, otros procesos de socializaciones y relaciones de poder en la conformación de la identidad. Esta noción de "conformación" da a entender que no es algo fijo, sino "un proceso abierto y ambiguo" (Quintana-Monge, 2016, p. 48), dada la dinamicidad de la vida social y sus múltiples espacios de actuación, en la que las personas entablan variadas relaciones, varias de ellas mediadas o condicionadas según el entramado de poder en que se encuentre la persona. Por consiguiente, acorde a Quintana-Monge (2016), en este enfoque no hay una sola identidad, sino múltiples, y jerarquizadas.

En el caso que nos compete, según se avance en la lectura, podrá notarse que, de acuerdo a los textos seleccionados, el malecu mantenía una visión esencialista de sí, en la que condicionaba su existencia, auto-denominación y adscripción al grupo si se cumplían ciertas características, o bien, si no se compartían aquellas características estereotipadas que atribuyeron a los pótos. No obstante, tal identidad está indefectiblemente atravesada o conformada por las relaciones que sostuvieron con los pótos, debido a que las prácticas y maneras de ser de este grupo indígena, como se podrá apreciar en el artículo, fueron una condicionante para la identidad del malecu.

Por ello, sin necesidad de caer en el dualismo antes mencionado, es mi consideración de que ciertamente hay auto-percepciones del endogrupo que son necesarias para atribuirse una pertenencia y ciertas cualidades para auto-denominarse y diferenciarse de otros grupos. No obstante, es mi postura que tal tipo de identificación, también está mediada por lo expuesto de la postura constructivista, dado que la identidad es gradual, no es estática, es aditiva, y están mediadas por procesos de (auto)descripción y adscripción (Weydt en Sánchez-Avendaño, 2015, p. 17-18). Como apunta Sen, la cuestión está en tener cuidado de la "filiación singular", es decir, suponer "que cualquier persona pertenece especialmente, para todos los propósitos prácticos, a una sola colectividad -ni más, ni menos-” (2007, p. 45). 
se configuraban su propia identidad, a partir de la representación negativa que hacían de los pótos. A diferencia de otras figuras como los ogros (muerra maráma) que representaban lo gravemente negativo, entendido en términos de daño, violación, muerte y falta de acatamiento a las reglas divinas, es decir, como "lo malo" en una figura que reunía estereotipos negativos con los cuales no se identificaban a sí mismos. Como toda función general del estereotipo, este consiste en atribuir a un colectivo características que tienden a ser principalmente peyorativas, y en algunos casos, degradantes ${ }^{12}$.

Dichas características estereotipadas no solamente conforman una manera de percibir al otro, sino que a su vez sirven para diferenciarse tangencialmente de tal colectivo, estableciendo para sí marcas o rasgos que se consideran propios (Cano-Gestoso, 1993, p.269; Casal-Madibeitia, 2005-6, p.137); a la vez que permite supuestamente justificar ciertos tipos de tratos, usualmente adversos y desfavorables, que pueden escalar hasta actos violentos de diversa índole.

Por tanto, el estereotipo llega a cumplir con la función de conformar -parcialmente- la identidad del grupo que genera tales características en el otro, en este caso, de los potos. Como se indicó, es en las "Pláticas de botos" en la que se encuentra principalmente la concepción peyorativa de los malecus respecto de los pótos, y en menor medida en las Pláticas sobre ogros, dado que los pótos eran víctimas preferenciales de los ogros. Esta apreciación negativa que los malecus construyeron en algún momento, se pueden agrupar en cinco grandes estereotipos, según se exponen a continuación.
Estereotipo de belleza. De acuerdo con lo que se desprende de los ciclos narrativos, la belleza era considerada como una cualidad natural, por lo que no se podía apelar a que lo bello no era más que simplemente un criterio subjetivo social ${ }^{13}$. Esto implica que el malecu se definió a sí mismo como un ser bello en contraposición al póto, pero enfatizando que estas diferencias no eran subjetivas a la visión que cada grupo podía tener de sí mismo, sino porque eran rasgos objetivos. No obstante, he considerado exponer la belleza no tanto como una idea que contribuye a configurar la identidad del malecu, sino como un estereotipo que da identidad, debido a que las caracterizaciones que los malecus hicieron en sus pláticas, fueron expuestas con burla implicando cierta denostación hacia el póto.

En primer lugar, los póto maráma eran vistos con algunas partes corpulentas, sin decir que fuesen necesariamente gordos o siquiera regordetes. De los hombres, se limitan a decir que "eran panzoncillos" (VI, p.143); mientras que con las mujeres enfatizaban en señalarlas como nalgonas (II, 19-20; III, 63), lo que de algún modo parecía ser un aspecto que se prestaba para la burla, debido a que los textos al mencionar que eran de nalgas grandes, lo hacen de tal manera que transmiten cierta jocosidad; máxime cuando se toma en cuenta que la narradora del texto III cuenta que su madre -quien le transmitió esta plática (III, 1-2 y 84-98)-, indicaba que a veces decían aspectos negativos de los pótos porque ellos (los malecus) "por gusto suelen hablar así en son de broma” (III, 90); por lo que se puede inferir que caracterizaciones, como las nalgas grandes u otras partes, tendían a la mofa.

\footnotetext{
11 A este respecto, puede verse Solano-Fallas (2019b), que aborda de manera detallada la figura del ogro como representación de los aspectos negativos (graves) con los que no se identificaba el malecu antiguo.

12 Dichas características pueden variar desde prejuicios hasta prácticas discriminatorias. En el caso de los prejuicios, pueden comprenderse como concepciones que emiten juicios de valor en detrimento de la persona o grupo al cual van dirigidas. Tales juicios pueden ser distorsiones de algún rasgo, práctica o hecho en particular, o bien no tener ningún vínculo real con la persona o colectivo. Por su parte, la discriminación puede entenderse como la puesta en práctica de tales prejuicios, en el momento en que la persona o grupo que mantiene sus prejuicios, entabla contacto con aquellos a quienes atribuye tales juicios. Claramente, tanto el prejuicio como la discriminación son temas complejos que en modo alguno pretenden discutirse acá, sino solamente evocarlos para comprender la noción del estereotipo.

13 Si bien es mi postura que lo bello es un constructo social al cual se le pueden relacionar otros conceptos, según los parámetros axiológicos que se posean en determinados momentos históricos (ver Eco y De Michele, 2010), en el presente trabajo expongo explicativamente la manera en qué era concebida la belleza por los malecus.
} 
En segundo lugar, se acentuaba que los pótos hombres eran "medio feíllos" (III, 29), de las cuales las mujeres tampoco eran una excepción, debido a que las consideraban igualmente "medio félllas" (III, 62). Parece que la idea de fealdad está ligada, parcialmente, a su corpulenticidad, debido a que el texto III después de que hace mención de que las mujeres son "medio feillas", indica: "y nalgudas nalgudas las mujeres” (III, 63). Fuera de lo regordete que está vinculado negativamente como un rasgo que hace que una persona no sea bella, no se tiene más información en estas pláticas de que otro factor constituye la fealdad.

Sin embargo, en una ocasión admitían que las mujeres eran de pechos bellos, cuando aluden a que "bellamente... se ungían las tetas con fruto de matapalo" (II, 21), y que los hombres no eran tan feos, por cuanto que "se veían bien con sus taparrabos" (II, 23). Por una parte, esto podría explicar porque no los consideraban categóricamente feos, sino "medio feíllos"; y otra, que evidencia el estereotipo ante ellos mismos, por cuanto que las líneas 21 y 23 confronta el propio estereotipo de belleza que los malecus conformaron en la figura de los pótos. Los catalogaban como seres que eran naturalmente "feíllos", pero se les filtró una apreciación de belleza: reconocieron por un momento que en belleza no son tan distintos al malecu, debido a que tales líneas indican por lo menos algún sentimiento de atracción. Aun así, se insistía en hacer de lo "medio feíllo" y lo corpulento de los pótos un estereotipo para encasillarlos como distintos y convertirlos en objetos de burla, a partir de criterios de belleza, que conducían a configurar la autopercepción del malecu.

Estereotipo intelectual. En términos generales se concibe a los pótos como seres intelectualmente inferiores, torpes, que no saben hacer gran cosa, según se puede inferir del siguiente listado de descripciones intelectivas negativas: "no eran muy listos" (I, 24), eran "atarantadillos” (II, 12), "eran ignorantes y como tales vivían” (III, 16), “eran insensatos” (III, 10, 30), “no razonaban bien” (IV, p.138), "eran atolondradillos” (IV, p.140), "eran despistados” (V, p.143), y "no entendían mayor cosa,/ eran tontos” (VII, 5-6). Incluso en Pláticas sobre ogros se expresaban "que... no... no... son listillos los votos" (XIII, 31). Obsérvese que los apelativos eran utilizados de manera general y omniabarcante, por lo que desde la perspectiva de los malecus, todos los póto maráma no podían no ser tontos. Algunos apelativos llegan a rayar en lo despreciativo, como llamarlos "atolondrados", "no muy listos", mientras que otros pasan tal raya convirtiéndose en denigradores, como cuando los catalogan de irremediablemente ignorantes por lo que no podían vivir de otra manera.

Cabe recalcar que los malecus no se limitaron a concebirlos como idiotas ignorantes, sino que su estereotipo abarcó la ineptitud para que estos se valieran por sí mismos. Al ser ignorantes y no poder dejarlo de ser, porque mentalmente ya tienen un problema intelectivo, de acuerdo a los textos $\mathrm{V}$ y VI, los pótos recurrían al robo de semillas de cacao, maíz, estacas de yuca, cepas de plátano, pejibaye, guaba, entre otras (V, 3, 14-18), y flechas (Texto VI) de los malecus, porque supuestamente no podían conseguirlas las semillas y demás, ni fabricar las flechas por sí mismos, lo cual despertaba la ira de los malecus, ya que los castigaban fuertemente mediante azotes (V, 12; VI, p.143), e incluso llegaban a matarlos (V, 12). Sin embargo, en una plática se llega a admitir que "[e]n efecto tenían de todo" (IV, p. 138), lo cual era un serio cuestionamiento a la noción prejuzgada que tenían del póto, debido a que "tener de todo" implica que efectivamente eran capaces de conseguirlo, lo que a su vez, valga señalar, presupone que no eran mentalmente deficientes. No obstante en las demás narraciones se insiste en proyectar el estereotipo. Por ejemplo, en el texto VI se vuelve a señalar que "De todo tenían" (VI, p. 143), pero seguidamente se indica que eran "despistados", lo cual parece ser un justificante para concluir que "No tenían cacao"; es decir, en el texto el malecu se estaba reafirmando a sí mismo que, a pesar de que los pótos se valiesen por su propia cuenta, eran unos ineficientes, y que por ello incurrían en el robo, porque no sabían hacer bien las cosas. Esta vacilación de estar afirmando una concepción prejuiciosa y a la vez asentir por breves instantes que no era cierto, no hacía más que manifestar ante el propio malecu su versión estereotipada del poto y el gran esfuerzo por creerla como verdadera, dado que los asentimientos 
de que efectivamente los potos "tenían de todo" sin duda alguna cuestionaban la noción que se habían conformado de este grupo indígena ${ }^{14}$.

De manera similar, su percepción intelectual sobre los pótos sirve de justificación para comprender que el póto no habla bien el idioma malecu: "no hablaban bien, pronunciaban bien... de otra manera, de otra manera las cosas,/ hablaban... distinto y no se les entendía su habla;/ se dice que hablaban por la nariz, no podían articular bien" (I, 65-67; idea similar se repite en III, 35 y VI, p. 143). Estas líneas presentan dos asuntos. En primer lugar, una persona debería -en principio- poder hablar bien, porque es lo suficientemente inteligente para comprender su propio idioma, empero, la idiotez se hace manifiesta incluso hasta en el habla. En segundo lugar, el hincapié que se hace en que el póto no habla bien el malecu, conduce a considerar que una persona se identifica con el resto de su grupo en el tanto que es un hablante de propio idioma. Es decir, el estereotipo de "menso que no puede hablar bien", implica que el hecho de hablar bien -entiéndase, tener conocimiento y dominio de su lenguaje- es un constitutivo de identidad. A pesar de que los pótos sean igual de humanos que los malecus, dado que Nharíne los creó al parecer conjuntamente (I, 2-3, 64-69; VII, p.147), el hecho de no poder comunicarse fluida y plenamente en malecu se convierte en una diferencia identitaria infranqueable, cuya deficiencia comunicativa se explica en términos de incapacidad mental. Por lo que desde la perspectiva malecu, este estereotipo conlleva a que no basta tener el mismo creador, sino que es imperioso conocer el idioma ${ }^{15}$.

Aunado a lo anterior, la deficiencia intelectual se notaba en que el póto, por un lado no era capaz de transmitir conocimientos de una generación a otra (I, 25; VII, 4), de lo cual se infiere que su saber fuese extremadamente limitado y constreñido a lo experiencial día a día. Por otro lado, lo poco que sabía, no lo sabía bien, lo que conllevaba a que no pudiese realizar bien las cosas por sí mismas, como ya quedó claro con la siembra y la fabricación de flechas. Pero también se menciona que su capacidad de realizar hechizos era restringida, por no tener mucho conocimiento (II, 32-33), y porque Nharíne no quiso transmitirles (II, 30).

Estereotipo emocional. Los pótos son considerados como emocionalmente extraños, por cuanto que tendían a alternar la risa, el llanto y el canto en momentos en que supuestamente las tres reacciones emocionales no deberían manifestarse, sino solamente una o bien ninguna según convenga la situación. Por ejemplo, si un ogro les robaba la esposa (II, 15-16; V, 28-30) o si se les moría un pariente (III, 20-25), se reían y luego lloraban, y después cantaban, y volvían otra vez a reír, llorar y cantar nuevamente, y así constantemente. En otros casos, en lugar de alternar el trío risa-llanto-canto, expresan una emoción que no correspondía al momento, por ejemplo, "si la esposa se les escapaba con o... o... otro, en verdad no más se reían y se reían,/ ¡qué iban a saber!, no entendían” (I, 26-27). La línea 27 es interesante, porque permite suponer que el desbalance emocional con el que caracterizaban a los pótos, se debía a la ineptitud mental que les nublaba su capacidad cognitiva para poder discernir que eventos requieren de risa o llanto o canto, o alguna otra emoción. Los malecus les reconocen que son seres que no pelean y que pasan cantando alegremente (II, 44-49), no obstante, les extraña sus reacciones emocionales. No las consideran normales, lo que implica que una persona debe tener control de sus emociones, sabiendo cuando es el momento indicado para ejercerlas.

Estereotipo sobre conducta laboriosa. Existía un esfuerzo en describir al póto como un ser dado a no trabajar mucho,

14 A este respecto, es interesante leer el comentario que realiza Eugenia Ibarra-Rojas a estas pláticas, debido a que desmiente la representación del póto como tonto-ladronzuelo: "En síntesis, los indios botos practicaron la agricultura, la pesca, la cacería y la recolección. De acuerdo con la información que brinda el conquistador español Marmolejo en 1563, eran capaces de producir para ellos y un poco más, que podían intercambiar, además del oro al que tenían acceso" (Ibarra-Rojas en Constenla-Umaña e Ibarra-Rojas, 2014, p.157).

15 Desde una perspectiva etnohistórica (Ibarra-Rojas) y lingüística (Constenla-Umaña), resulta fácil comprender el posible origen de la particularidad del estereotipo en relación al idioma "mal hablado" por parte de los pótos. Los pótos tenían la capacidad de hablar de manera errónea el malecu, y de entenderlo a pesar de las confusiones, porque los pótos hablaban un idioma emparentado al malecu, y por tanto no propiamente el malecu. El idioma que hablaban era el rama, el cual pertenecía, junto al malecu y posiblemente el huetar, a la familia vótica de la estirpe chibchense nuclear (Constenla-Umaña, 2011, p.95; 2014, p.4; e Ibarra-Rojas en Constenla-Umaña e Ibarra-Rojas, 2014, p.114). 
sin catalogarlo como un vago sin remedio, pero tampoco de presentarlo como un ser excelsamente laborioso: "no eran tan vagos los botos,/ en efecto trabajaban,/ en efecto sembraban yuca,/ en efecto sembraban plátano,/ en efecto hacían chicha,/ en efecto hacían chicha de plátano verde ahumado" (II, 5-10). La visión que se configuraba el malecu del póto, confrontada con la realidad, lo obligaba a aceptar que sin duda que el póto realizaba algunas labores agrícolas, cuando afirma expresamente que "en efecto eran trabajadores,/ en efecto sembraban cacao,/ en efecto sembraban yuca" (III, 13-15). Empero, al ser el otro diferente, le menoscababa parcialmente dicho mérito al comentar insistentemente en que a pesar de poder sembrar, no era un gran trabajador, porque no se dedicaba afanosamente al trabajo: "en efecto, trabajaban, sembraban yuca, pero poca solamente, sembraban cacao, pero po... pero poco solamente" (VI, p.143). De este modo, se conformaba la idea que, si bien admiten que los pótos sabían trabajar, a pesar de su pretendida deficiencia mental, la razón por la cual no lo hacían parecería ser más por un asunto de vagancia y pereza, cuando se vuelve a rematar que "[e]n efecto trabajaban, pero no... mucho" (IV, p.138). Solamente en un texto, se llegó al extremo de aseverar que del todo no eran laboriosos, debido a "que los botos no trabajaban,/ andaban en la selva no más, se estaban echados en breñales” (I, 13-14), lo cual da una idea de holgazanería en la que no hacían más que perder el tiempo. Este último texto es un indicador de la intención del malecu en hacer de ellos personas del todo no trabajadoras, sin embargo, su estereotipo es atenuado. A diferencia de los otros estereotipos en que a "regañadientes" contradecían su propia noción prejuiciosa, en este estereotipo no lograron o no quisieron negar la evidente realidad de que si hacían algo, por lo que se limitaron a menoscabar parcialmente su actitud laboriosa.

Estereotipo sobre conducta sexual. En términos generales los pótos fueron calificados como "muy fregados" (II, 2) o "tremendos" (II, 65), lo que da a entender en el lenguaje coloquial costarricense actual como "calenturientos". De acuerdo al primer texto, no había hombre que no pudiese ver una mujer y no sentir deseos (II, 3-4), e igualmente las mujeres tampoco se recataban, por cuanto que "con hombres... se daban gusto" (II, 36), por lo que se puede deducir someramente que tenían una vida sexual sin mucha restricción, sin caer en prácticas sexuales que los Dioses (tocú maráma) detestaban en demasía, por ejemplo, la homosexualidad y la incestuosidad, o peor aún -desde la perspectiva malecu tradicional- en la mezcla de ambas, y aún más terrible, que fuesen a gran escala, es decir, en orgías homosexuales incestuosas. Recuérdese que la conducta sexual es uno de los puntos que los Dioses exhortan constantemente a los malecus, por ejemplo en el Laca Majifijica, el segundo castigo se debió por relaciones sexuales incestuosas lésbicas, y el tercer castigo, que es en sí la transformación de la tierra, fue a causa de las orgías incestuosas homosexuales en las que incurrieron tanto hombres y mujeres. Asimismo, este aspecto vuelve a ser retomado en las Pláticas sobre ogros, en la que los malecus hacen del ogro un desenfrenado sexual, abusador, asesino e incestuoso: rasgos que son utilizados para atribuir a esos seres aquellas características con las que no se identifican. Obsérvese que, a pesar de que los pótos son estereotipados, no se llegó a exagerar ni proyectar en tales indígenas los rasgos que los propios malecus consideraban negativamente perniciosos respecto de la conducta sexual, como por ejemplo si se los atribuyeron a los ogros.

De manera similar como ocurrió con el estereotipo de la conducta laboriosa, los malecus no pudieron o no quisieron negar la realidad de la vida sexual de sus congéneres humanos. Empero, ello no les impidió en presentarlos como seres con muchos deseos sexuales, a tal punto que expresaron de que "[n]o tenían pudor" (III, 11), que de acuerdo a Constenla-Umaña, quería decir que "[n] o les da pena ver o tener relaciones sexuales ante todo el mundo" (en Constenla-Umaña e Ibarra-Rojas, 2014, p. 135; nota \#1). Esta impetuosidad sexual es llamativa, porque los pótos no se limitaban a tener relaciones sexuales entre su propia gente, sino que al parecer seducían a los malecus, ya que "con hombres de acá y acullá fornicaban ellas,/ con mujeres de acá y acullá fornicaban ellos" (II, 36-38). Nótese que no dicen que fornicasen a la fuerza con los y las malecus, sino que las líneas presuponen que había un consenso sexual de ambas partes. Considero que es llamativo, por cuanto que este señalamiento viene a contradecir nuevamente el estereotipo de la belleza: si los pótos fuesen bastante "feíllos", resultaría difícil explicar con cuál "encanto" conseguían tener sexo con 
malecus, dado que la violación es descartada en las narraciones como opción para explicar estos encuentros sexuales. Sería especular demasiado en que resultaban excelentes amantes sexuales, y que por esto los y las malecus accedían a las relaciones sexuales; no obstante, deja entrever una vez más como el estereotipo de belleza es cuestionable, lo que a su vez conduce a plantear que el estereotipo de la conducta sexual era un intento más por concebir que la "tremendosidad sexual" era un rasgo propio del póto, y no del malecu.

Por otra parte, los malecus veían en esta conducta sexual el efecto que tenía la deficiencia mental, dado que expresaban que "[e]n verdad tan solo sucedía que no razonaban bien y... podían estar juntos, estar dos hombres... con una misma mujer" (IV, p.138). En primer lugar, les llamaba la atención que dos hombres estuviesen dispuestos a compartir una misma mujer. Como primer subpunto, esto denota que a la mujer se le reconocía una sexualidad de la cual podía disfrutar, dado que los textos no presentan una censura del actuar sexual femenino, siempre y cuando no se cayese en orgías, ni mucho menos lésbicas. Empero, como segundo subpunto, lo anterior revela un valor patriarcal malecu en el tanto que en la mujer no podía ser sujeto que dispusiese de dos hombres para su gozo, mientras que el hombre si podía estar con dos o más mujeres. Cabe aclarar que esta práctica sexual no implicaba que fuese un trío, es decir, que las tres personas estuviesen juntas en el mismo momento, sino a convivir. De acuerdo a Constenla-Umaña, "en materia de matrimonio, practicaban la poliandria, rasgo este último que particularmente chocante y chistoso para los guatusos, entre los cuales lo que se daba era la poliginia" (2014, p.5), lo cual contribuía a considerar a los pótos como los otros que se comportaban sexualmente extraños respecto de lo que se suponía ser lo correcto. En segundo lugar, se muestra como tal práctica sexual -y matrimonial, según parece ser, como menciona Constenla-Umañano podría ser producto de una persona inteligente, sino solamente de alguien que no estaba en capacidad de razonar "adecuadamente".
Aunque admiten que habían excepciones, debido a que habían algunos póto maráma que vivían en monogamia: "en efecto existían... quienes eran así,/ y... se conformaban con la esposa, se conformaban con el esposo" (II, 3940). No obstante, dicha excepción no parece ser más que una validación del estereotipo, en el tanto en que estaban calificando a estos pótos monógamos como irregularidades dentro de su propio grupo, sin que ello implicase una identificación con los malecus, y por ende, que tampoco hubiese una negación de la noción generalizada que habían conformado los malecus.

Relacionado a la permisividad sexual, de acuerdo a los malecus, los pótos cuando se convertían en padres -y podría incluirse a las madres- tampoco practicaban una restricción de la impetuosidad sexual de sus hijos, ni mucho menos incurrían en prohibirles a sus hijos las parejas sexuales, tal como se infiere del siguiente texto: "no tenían celos de los otros botos... por sus hijas, como... los otros, los arimimis, los corocus, los jafanhjis, en absoluto" (VII, p.149). En primer lugar, esto explicaba para los malecus porque dentro del propio grupo indígena póto, no había inconveniente alguno en que se llevase a cabo la "tremendosidad": los padres y las madres, antes de ser tales, disfrutaban de su vida sexual, lo que implica que sus propios padres y madres no ejercían ningún dominio sobre su sexualidad; lo que conduce a plantear que este permisivismo parece ser una conducta parental que se reproducía con la siguiente generación, y así sucesivamente. Por lo que hubiera parecido extraño que antes de asumir la paternidad, no hubiese habido inconveniente alguno con quien se sostuviese sexo dentro de los límites permitidos por los Dioses-, pero que luego de la paternidad, se hubiesen tornado selectivos con las parejas de sus hijos. De ahí que el texto indique que no existía inconveniente o "celos" sobre cuál póto gozase del hijo/hija del otro, porque el padre/madre así lo hacía antes de la paternidad-maternidad. En segundo lugar, el texto denota que tales "celos" si eran un asunto a considerar antiguamente por los malecus. Los tres nombres que se indican, a saber, arimimis, los corocus, los jafanhjis, correspondía a por lo menos tres linajes 
patrilineales malecus que alguna vez existieron (SánchezAvendaño, 2015, p.57) ${ }^{16}$; por lo que al haber existido linajes, la fogosidad sexual de los hijos no podía ser permitida por los padres, dado que había un orden a relacionarse.

Podría considerarse que la existencia de linajes, y particularmente patrilineales (Sánchez-Avendaño, 2015, p.57), que salen a relucir, constituyen la razón última del estereotipo mismo: los malecus no podían ver como normal dicha conducta sexual, porque era incompatible con la manera con que dividía organizativamente su pueblo. Un pueblo que se encuentre dividido patrilinealmente, no podía permitir que los hijos de cada linaje gozasen sexualmente con cualquier malecu, como tampoco que dos hombres compartiesen una mujer, debido a que sus linajes se hubiesen perdido; lo cual podría interpretarse que el ser "fregados" como un acto "carente" de sensatez, siendo precisamente esto lo que veían en los pótos: insensatos, tontos, atolondrados, sin pudor, que no comprenden las implicaciones sociopolíticas que implicaban los actos sexuales.

De este modo, básicamente consideraron que el póto era de costumbres raras (III, 20; esta idea se repite con insistencia en líneas 9 y 17). Además de lo emocional y lo sexual, se menciona que eran raros por montar sus casas sobre los árboles (I, 8; III, 67), por echarse a dormir en las gambas de los tamarindos (I, 19), de las ceibas (I, 20), y en general de cualquier gamba (III, 18), cuando andaban en la selva y les caía la noche. También se les llamaban extraños por el proceso que seguían en los entierros (VII) ${ }^{17}$. En el texto III de Pláticas sobre ogros, se menciona una costumbre alimenticia que consistía en comer danta, la cual era considerada por lo malecus como un animal impuro, según mandato de los Dioses. Otra costumbre alimenticia aparece en "Pláticas de bótos", la cual era comer, en demasía, comida de ardilla, lo que resultaba insólito para los malecus (V, 1925). Todo esto contribuye a reforzar la concepción negativa y peyorativa. El póto era un ser "medio feíllo", parcialmente por ser regordete, y por otras razones que no quedan claras; no era inteligente, lo que lo hacía supuestamente incapaz de valerse por sí mismo (por lo que recurre al robo), como de tampoco poder hablar bien, e incompetente para poder transmitir conocimiento y aplicar adecuadamente el poco saber del cual disponía; era emocionalmente inestable, dado que no sabía discernir en qué situación ejercer alguna o ninguna emoción; era más o menos vago, que si bien trabajaba, no lo hacía con muchas ganas; y finalmente un "tremendo" sexual, no pudoroso, cuyo matrimonio tendía a ser de dos hombre y una mujer, y sin restringir o seleccionar las parejas de sus hijos.

Los cinco estereotipos que el malecu le atribuye al póto, en primera instancia les eran de utilidad para calificar al "vecino", brindándoles una concepción -si bien errónea y muy parcializada- con quién estaban tratando; máxime que son sus congéneres, debido a que Nharíne los creó.

16 Según comenta Sánchez-Avendaño, "la unidad política parecía ser la comunidad o conglomerado de familias unidas por parentesco, liderada por el fundador del palenque o uno de sus descendientes, el individuo más anciano o incluso un vidente” (2015, p.57). Por su parte, los linajes eran el modo por el cual se dividía el pueblo antiguamente, sin presuponer grandes diferencias de estatus, rango o prestigio, por cada linaje. Aclara que actualmente se desconoce cómo se organizaba cada linaje, salvo en que no consistían en comportarse como clanes, es decir, que la exogamia no era exigida.

17 Básicamente, el texto narra que los pótos enterraban al difunto al tercer amanecer (día), sin colocarle las tablas por encima y debajo del cuerpo. Durante los dos amaneceres, el cuerpo permanecía expuesto, sin embargo, en qué condiciones no queda claro, dado que el narrador parece vacilar: en un primer momento dice que era cubierto de una resina (VII, p.147) -que el narrador no especificó, probablemente porque no se acordaba o no tenía conocimiento-; más adelante señala que lo envolvían en mastate, y le pintaban un poco los arcos ciliares pero que "en verdad no lo pintaban” (VII, p.148). A este respecto, Ibarra-Rojas (en Constenla-Umaña e Ibarra-Rojas, 2014, p.16o) confirma que efectivamente ocurría al tercer día, y aclara lo que parece ser la vacilación del narrador. En los primeros días de muerto se le cubría con resina, aunque parece que en ocasiones variaban dado que lo pintaban. Al tercer día si lo pintaban con achiote y lo envolvían en mastate. De esta manera, la vacilación que se observa en el texto, parece deberse a falta de claridad expositiva del narrador.

Por otra parte, el texto proyecta el estereotipo de inteligencia, por cuanto que decían que los pótos se preguntaban si el difunto estaba muerto, y que lo vigilaban para ver si se iría a levantar, o hablar, o alzar los brazos (VII, p. 147-148), o cualquier otra cosa.

Los malecus consideraron este proceso de enterramiento extraño, dado que su práctica consistía en que la persona debía ser enterrada al amanecer siguiente que había muerto, colocándole tablas por debajo y encima de su cuerpo, para quedase en contacto directo con la tierra (Constenla-Umaña en Constenla-Umaña e Ibarra-Rojas, 2014, p.150, nota \#11). En relación al texto VII, parecería que también era una práctica que fuese pintado, aunque Sánchez-Avendaño menciona que Sapper informaba que a finales del siglo XIX, el cuerpo era envuelto en mastate, después de que había sido vestido con un traje nuevo, y se le colocaban bananos, cacao y materiales para hacer fuego (2015, p.70). 
Pero más allá que esto, la versión estereotipada fue relevante para construir la imagen que tenían de sí mismos, e identificarse como un solo colectivo, debido a que "[c]uando los individuos se identifican con un grupo y observan al resto como miembros de otro grupo distinto al propio, se tiende a despersonalizar a los demás, considerándolos como personas que reaccionan de un modo determinado por pertenecer a un determinado grupo y no como individuos con rasgos personales o diferencias con su propio grupo" (Casal-Madinabeitia, 2005-6, p.140). En primer lugar, como se indicó en su momento, el malecu se veía a sí mismo como el parámetro del cual juzgar la belleza de los demás, y por ende, como bello. El simple hecho de que se destaque burlescamente las grandes nalgas de las pótas, y el que ambos sexo-géneros sean regordetes, indican que se concebían con mejores atributos físicos. Aun cuando se les filtró apreciaciones de belleza en los pótos, insistieron en que eran "medio feíllos".

En segundo lugar, se consideraban a sí mismos inteligentes, por cuanto que tenía un mayor cúmulo de conocimientos, por lo menos en hechicerías, siembra y fabricación de flechas: se puede inferir que sus hechizos eran más efectivos por la comparación ineficaz que se hace con el póto; sabían sembrar porque no tenían necesidad de incurrir en robos, debido a que la narración asocia robo con no saber sembrar, por lo que infiere que el saber sembrar no implica robar, desde su argumentación lógica; y de manera similar se puede decir de la fabricación de flechas, dado que al no incurrir en robo, significa que conocen y ejercen las respectivas técnicas para crear flechas. Además, por contraposición al póto, eran capaces de transmitir dichos conocimientos de generación en generación. El aspecto más relevante de verse como inteligentes, tenía que ver con el manejo del idioma, debido a que el conocimiento y el uso del mismo era indispensable para llamarse a sí mismo malecu. Nótese que si bien los pótos son sus congéneres porque el mismo Dios los creó, enfatizaron en que eran ajenos de la "malecuidad" porque ni siquiera podían hablar correctamente; por lo que el dominio del idioma era un indicador de quién es malecu, lo cual presuponía a su vez una capacidad cognitiva.

En tercer lugar, como se había comentado, el malecu se veía a sí mismo como un ser capaz de controlar sus emociones, y de saber en cuál situación corresponde manifestar una o varias. Esto está claramente ligado al aspecto anterior, por cuanto que consideraba que solamente un ser inteligente actúa sensatamente.

En cuarto lugar, se concebía con una actitud trabajadora, dado que el hecho de que supiese sembrar y fabricar flechas, manifestaba que no solamente laboraba, sino que lo hacía con empeño, porque no se veía en la necesidad de robar. Si bien admite que el póto hace algo de trabajo, pero que vaguea, se autoconstituye como ejemplo de laboriosidad, por cuanto que criticar al póto por "medio trabajar", presupone que había un criterio a seguir, el cual no era otro más que sí. De ahí que se pueda inferir que una persona que verdaderamente se identifique como trabajador, no puede serlo si a la vez es perezoso. La pereza o vagancia es una cualidad negativa que era rechazada, por no permitir el adecuado desarrollo de las actividades, en este caso, agrícola y fabril.

En quinto lugar, el malecu llegó a verse a sí como un ser que controlaba sus impulsos sexuales, por cuanto que no estaba deseando mantener relaciones sexuales con cuanta persona del sexo-género opuesto se le cruzase por el camino. Esto no quiere decir que practicase la abstinencia de manera generalizada, pero que por lo menos mantenía una conducta sexual moderada marcada por el pudor, dado que no llevaba a cabo sus encuentros sexuales en público. Además de controlar su fogosidad, también se concebía como racional en materia sexual, debido a que estaba consciente que el sexo desenfrenado podía traer consecuencias negativas a la organización y división del pueblo. Recuérdese que los linajes patrilineales servían como un mecanismo de clasificación, por lo que una sexualidad irresponsable podía afectar el orden establecido. De ahí la importancia de velar por la vida sexual de los hijos, como también de ver como una insensatez el que dos hombres compartiesen a una misma mujer, dado que se interrumpiría la manera "racional" de dividir al pueblo según linajes, ya que no se sabría a cuál pertenecería el hijo. Sin embargo, esta noción que se dio a partir del estereotipo del póto, tiene un inconveniente. El malecu se proyectó como una persona que controlaba su sexualidad, y que la enmarcaba dentro de la racionalidad, pero en la práctica no cumplió según la manera con que se identificaba a sí mismo. De los pótos, por más "fregados" o "tremendos" que fuesen, tendían a conducirse de manera adecuada, por lo 
menos en términos generales, ya que "en realidad si hacían cosas incorrectas, solo que no muchas en verdad pues" (IV, p.140). Dentro de las cosas incorrectas, que se podría citar el comer danta y la permisividad sexual, ninguna llegó a ser razón suficiente para que Nharíne decidiese transformar la tierra. Cuando Aóre instiga a Nharíne, y este finalmente accede, fue por el comportamiento sexual incestuoso y homosexual de los malecus, no por la fogosidad de pótos, debido a que estos -salvo algunas excepciones- murieron de buena manera antes del cataclismo (II, 56-59, 71; III, 68-70, 79-83; VI, p.143; y VII, p.149). Esto es revelador de la verdadera conducta sexual del malecu, a pesar de que trataron de negarla, y desviar el asunto en la impetuosa sexualidad del póto, a tal punto que obviaron que los encuentros sexuales entre pótos y malecus parecen haberse debido por un mutuo consenso, lo que claramente cuestiona la propia racionalidad sexual que se atribuían.

Hasta aquí se tiene que a costa de los estereotipos con los que circunscribió al póto, el malecu consolidó su identidad en términos positivos como una persona que es bella, inteligente, emocionalmente estable, laboriosa y sexualmente moderada (aunque en este último punto falló terriblemente). No obstante, los estereotipos de los cuales se valió para configurar su identidad revelan por lo menos dos aspectos negativos que el malecu no quiso admitir, y mucho menos identificarlos como parte de quien era o se proyectaba ser. En primer lugar, al contrastarse con los pótos quienes son caracterizados como gente que no peleaba, y que por el contrario, se la pasaban cantando (II, 44-49), se deja entrever que el malecu podía ser agresivo, aunque no se identificase explícitamente como tal. Sin embargo, se infiere que podía ser agresivo, no solamente porque mantuviese las características de pacífico y alegre como distintivos del póto, y no las remitiese a sí mismo, sino también porque los castigos que le infligía a los pótos que les robaban eran bastante duros, al punto que llegaban a matarlos. Por lo que a pesar suyo, la manera en que trataba a los pótos denota que hacían uso de la agresión. Quizá esto no los identifique como agresivos, pero por lo menos como potenciales agresores o agresores ocasionales; rasgo con el cual los textos no parecerían estar de acuerdo, debido a que, en su lógica, los actos agresivos son constituyentes de un ser agresivo, según se aprecia en la figura del ogro ${ }^{18}$. En segundo lugar, como se comentó en relación a la "tremendosidad", el malecu no se permitía -por lo menos en el discurso- la permisividad sexual, empero, sucumbía al sexo irresponsable, sobrepasando a los póto maráma, por cuanto que estos no cayeron en orgías incestuosas y homosexuales. De este modo, contra su propio parecer, su identidad incorpora la propensión a la agresividad, como también una conducta sexual proclive a la tentación.

En cuanto al etnocentrismo que es claramente evidente en los textos, desde el marco cultural occidental actual de Derechos Humanos, es y debería ser una práctica que debe ser eliminada, en el tanto que no permite un adecuado acercamiento con el otro por la distorsión a la cual es sujeto ${ }^{19}$. Por lo que parecería, en principio, como un rasgo negativo de la identidad malecu antigua. Empero, explica Ibarra-Rojas que "es un rasgo común entre algunos pueblos indígenas centroamericanos, por lo menos" (en Constenla-Umaña e Ibarra-Rojas, 2014, p.157). Por lo que no era atípico, aunque llama la atención que lo aplicase al póto, quien se supone ser un congénere suyo, creado por el mismísimo Nharíne, quien en varias ocasiones les pidió que no lo tratasen mal. A pesar de la solicitud divina, habían decidido hacer del póto objeto de burla, según cuenta la narradora del texto III, cuando explica que su madre le contaba que "por gusto suelen hablar así en son de broma” (III, 9o) respecto del póto. Incluso ese mismo texto indica que esta visión peyorativa había sido

18 En Pláticas sobre ogros, se había puesto la agresividad como un rasgo en la figura del ogro, y por tanto, no propio de sí.

19 Esta idea en contra del etnocentrismo, considero que tiene su respaldo, por ejemplo, en el artículo 19 de la Convención Mundial de Derechos Humanos de Viena de 1993 (Naciones Unidas, 2013), el cual indica lo siguiente: "Las personas pertenecientes a minorías tienen derecho a su propia cultura, a profesar y practicar su religión y a emplear su propio idioma en público y en privado, con toda libertad y sin injerencia ni discriminación alguna”.

Si se efectúa una lectura (claramente anacrónica) de la situación de los pótos desde el Art. 19, resulta manifiesto que las prácticas emprendidas por los malecus, según se hallan en sus narraciones, contribuían a una manera de negarles y desdeñar la cultura de los pótos. Nótese la manera en son marginados por sus distintas prácticas laborales y sexuales, e incluso el modo en que expresaban sus emociones, dado que no coincidían con aquellas que los malecus consideraban correctas y propias de todo malecu. Incluso hasta la forma en que pronunciaban el malecu jaica era objeto de burla. 
heredada por dos linajes: "se les había metido el prejuicio en la cabeza a los jafanjis y a los corocus/. y pensaban... que eran tontitos" (III, 53-54); lo cual es interesante porque ubica a los responsables, o por lo menos a los colectivos grupales, dado que no puntualiza en personas concretas. Con todo reconociendo que la visión negativa sobre el póto es utilizada abiertamente para mofarse, y que fueron dos linajes antepasados quienes introdujeron dicho prejuicio, el estereotipo del póto se presentaba como normalizado, y por ende, se muestra con naturalidad el rasgo etnocéntrico del malecu antiguo.

\section{Aliciente moral}

La visión peyorativa sobre el póto conducía a configurar la identidad que el malecu tenía de sí, y a su vez dejaba entrever no solamente rasgos etnocéntricos, sino cualidades negativas que buscaba opacar, pero que se hacían manifiestas en las pláticas. Además de esto, los estereotipos cumplían otra función, a saber, ser estímulos morales para propiciar o rechazar ciertas conductas, dado que "el estereotipo es concebido como un refuerzo positivo o negativo con el que se intenta controlar la conducta de los miembros del grupo" (Cano-Gestoso, 1993, p.236). En términos generales, se podría decir que aquellos aspectos negativos se rechazarían porque eran supuestamente propios de los pótos, lo cual vendría a decir, que solo los tontos, insensatos, ignorantes, los realizan; o bien, que los aspectos positivos que se vinculan al póto, sería como decir que si incluso "los tontitos" se comportan de X-manera, por qué no también los malecus, quienes se consideran superiores que ellos, lo que de alguno modo equivaldría a golpear el ego en orden promover una conducta.

En cuanto a los aspectos negativos, la figura prejuiciada del póto, conducía a condenar socialmente la actitud vagabunda y perezosa, y por ende, a proyectar como valor el tener una actitud laboriosa. El trabajo se constituía como rasgo importante que todo malecu debía cumplir, no solamente por la mera razón existencial de primer orden, a saber, alimentarse y protegerse, sino también porque le permitía poner en práctica lo que había aprendido, y lo que los Dioses les habían enseñado. Trabajando es como el malecu se realizaba plenamente, tanto a nivel individual como grupal, ya que su esfuerzo no solamente lo beneficiaba, sino que conducía a la preservación y mejoramiento de su pueblo, debido a que el malecu no se concebía como un ser aislado, sino como parte del palenque. En otras ocasiones me he referido a que la elección es un tema importante para el pensamiento malecu, dadas las consecuencias que tiene el actuar moral (Solano-Fallas, 2016, 2018 y 2019a). En este caso, se podría decir que si el malecu decide no trabajar encarecidamente y vagabundear como del afirma póto, su decisión no sería un asunto que lo afectase únicamente a él/ella, sino que de algún modo tendría implicaciones en la subsistencia y organización de su pueblo, como también de sus relaciones interpersonales con sus congéneres malecus. Por otra parte, si no trabajaba, se vería forzado a robar en orden a poder alimentarse, lo cual podría poner su vida en peligro, tal y como ellos mismos hacían con los pótos. El duro castigo que infligían, en primera instancia, pretendió ser un medio disuasivo para los pótos, en orden a hacerles saber lo que les podría pasar si incurrían nuevamente; pero podría inferirse que también sirvió para asustar a los propios miembros, debido a que estas pláticas, como muchas otras, tenían por finalidad ser edificantes morales (cf. Constenla-Umaña 1992, p.88; 1993, p.19; 2011a, p.10; 2014, p.16). Así, quien no trabajase, se estaría comportando como un póto, y como tal, merece el "debido" castigo.

Otro aspecto negativo que se buscaba disuadir mediante el póto, era la conducta sexual permisiva. Como se explicó anteriormente, el tener sexo con cualquier persona, o que dos hombres conviviesen con una misma mujer, tenía implicaciones en la organización interna del pueblo malecu, dada la existencia de linajes patrilineales. No se podía ejercer una sexualidad irresponsable, sin pensar nuevamente en el impacto que ocasionaría en el endogrupo, dado que la persona no se encuentra separada del todo. Por otra parte, el mantener encuentros sexuales carentes de pudor, es decir, en pleno público, es aducido como un comportamiento que solamente un tonto-que-no-sabe-loque-hace haría. Juzgando por el contenido de los textos, no parece deducirse, o siquiera inferirse, que los malecus cayesen en la falta de pudor, no obstante, se plantea como una conducta que ningún ser racional debería de imitar. A los pótos se les condonaba, no porque estuviese correcta, sino que por su deficiencia mental no tenían consciencia de lo que hacían. Por tanto, un malecu no podría apelar a que 
no tenía conocimiento de la gravedad en la que incurría, por cuanto que se identifica como un ser inteligente. Este aliciente resulta llamativo, en el tanto en que era un punto en el cual tendían flaquear, y que por ende no siempre seguían cabalmente; y que aun así atribuyeron como exclusivamente propio del póto, mientras obviaban que varios de los suyos se dejaban seducir por los pótos. Quizá, de ahí su mayor insistencia e importancia en las narraciones malecus, dado que por algunos tipos de conductas sexuales fueron eliminados de la tierra, mediante el cataclismo.

En lo que respecta a los aspectos positivos, relucen por lo menos cuatro, que a pesar de provenir de seres "mensos", los reconocieron como comportamientos positivos. En primer lugar, se indica que "no... bebían mucha chicha de yuca, no... se emborrachaban mucho, en verdad, solo... tomaban para llenarse" (VII, p.149), por lo que surge como aliciente el no beber -bebidas fermentadas- en demasía. Si los pótos por ser ignorantes y no saber lo que hacían, y aun así no eran unos borrachos, mucho menos podían serlos los malecus. De las "Pláticas de botos" no se sugiere que los malecus fuesen unos alcohólicos, empero reconocían al congénere inferior no abusar de la chicha. No se sigue que vetasen toda bebida fermentada, sino que su engerimiento se realizaba dentro de límites racionales.

En segundo lugar, se comenta que no eran seres que gustaban de pelear. De manera general, el texto I dice que "[n]o hacen daño" (I, 29), lo cual puede interpretarse que no perjudicaban a ningún otra persona, ni siquiera a los malecus, por cuanto que estos últimos tendían a ser los victimarios de su desmedido castigo por robarles semillas y flechas. De manera más concreta, se señala que "no se peleaban" (VII, p.149), lo que da a entender que entre ellos mismos no resolvían sus problemas con algún grado de violencia ${ }^{20}$. Sin embargo, a pesar de reconocer en los pótos este aspecto como positivo, en la práctica no estaban plenamente dispuestos a seguirlo. Los malecus en las chichadas efectuaban luchas con bordones (SánchezAvendaño, 2015, p.64). Si bien no se consideraban a sí mismos agresivos, ni mucho menos agresores, el hacer de las peleas un entretenimiento, denota que requerían de un medio para canalizar rasgos agresivos que niegan en el discurso, pero que la práctica desmiente. Aunado a esto, Rigoberto Lacayo (malecu del Palenque Margarita) señala que "[c]uando había una rivalidad entre los hombres por una mujer, tenían que pelear entre los dos” (en J.E.P. Margarita-IETSAY 2000, p.74), con palos especiales en el que cada pretendiente golpeaba una parte del cuerpo de su contrincante, por turnos, hasta que uno de los dos cayese, pero sin que se le matase. De igual modo, no se consideraban peleoneros, y aun cuando minimizaban los efectos mortales de una pelea, el mero hecho de que tuviesen que acudir a una para decidir quién se quedaba con una mujer, denota nuevamente un quiebre en la autoimagen. En todo caso, el punto consiste en que reconocían que la figura del póto era un aliciente para no pelear, pero sus conductas revelan que, si bien no pasaban peleando todo el tiempo, hacían de la pelea un medio de entretenimiento y un arbitraje.

En tercer lugar, lapidariamente se puntualiza que los pótos "no hablan obscenidades" (I, 30), lo cual se intuye como un rasgo a seguir, porque seguidamente se indica en el texto que esto era parte del buen comportamiento que Nharíne observaba en ellos. A partir de estas pláticas -como otras que son de mi conocimiento- no se sugiere que el malecu fuese malhablado y vulgar, y que por tanto utilizase la figura del póto para auto-llamarse la atención. A lo sumo se puede conjeturar que si dichos "tonticos" no son unos obscenos, con mucha mayor razón no podían serlo los malecu, por lo que quizá este aspecto positivo fungiese como un recordatorio a continuar siendo decente en el habla. Es decir, sería un aliciente que refuerza una conducta que ya estaban siguiendo.

Finalmente, se halla un cuarto aspecto positivo que

20 En Pláticas sobre ogros, acaecen unas excepciones. En el texto II, un par de amigos fueron al otro lado del río, el cual cruzaron con un mecate. De regreso, el amigo (protagonista de la narración) cruza primero y retira la cuerda, para que los ogros viniesen por su amigo y lo devorasen, y así el quedarse con la esposa. Al final, el amigo traicionado logra cruzar al día siguiente, gracias a la ayuda de su collar-amuleto que le indicó que tenía que hacer. Una vez que llega a la casa, cuenta lo sucedido, y él y otros le dan una paliza al amigo traidor, por tratar de robarle la esposa y matarlo. En el texto III, un póto le da a su coesposo carne asada de un ogro que habían matado, engañándole que es de danta, para que este muriera y quedarse solamente para sí con la esposa que compartían. A raíz de esto, el coesposo muere, pero se convierte en un alma condena por la muerte violenta que tuvo. En ambos textos resalta el hecho de que efectivamente se daban peleas entre los mismos pótos, no obstante, parecen ser casos aislados y muy ocasionales, por lo que la idea de que el póto no es peleonero se mantiene. 
tiene que ver con el cuido y protección de los árboles, que figura solamente en la última plática (VIII). En ella se narra que, en primer lugar, cortar los árboles es como asesinar un ser, debido a que lloran cuando son cortados (VIII, 2), y que sangran, dado que la savia que les corre es su sangre (VIII, 3). En segundo lugar, el cortar/matar un árbol no solamente afecta al árbol en cuestión, sino también a la flora circundante, dado que estos cumplen distintas funciones en el ambiente. Por ejemplo, se cita que los mangles protegen las lagunitas (VIII, 6-8). Obsérvese que esta plática plantea una ética ambiental, cuya preocupación principal no es el humano -quien sin duda se vería afectado a la larga-, sino en la conservación del propio ambiente, por cuanto que este tiene un valor por sí mismo y no en relación a los seres humanos, debido a que fue Nharíne quien creó todo, sin caer un antropocentrismo desmesurado y tiránico sobre toda la naturaleza. Por el contrario, el ser humano debe saber cómo existir en grupo y, como tal, co-existir con el ambiente, según se muestra en la queja que plantea el texto: se dice que los Dioses le habían dicho a un malecu que no cortaran árboles, "[p]ero ahora ya no obedecen [los malecus]./ A todos todos (sic) esos tipos de cosas las cortan” (VIII, 10-11), mientras que un póto, después de haber cortado un árbol, este le reclamó por qué lo dañaba si no le había hecho nada, por lo que ante la perplejidad de que el árbol le hablase y le reclamase, sin poder entender lo que estaba sucediendo, Nharíne se le presentó indicándole que no quería que él -y por extensión, sus congéneres pótos- cortasen más árboles, excepto aquel del cual se obtiene leña (VIII, 23-25). Por el contexto de la plática, parece que el malecu antiguo en algún momento sucumbió en la tala irresponsable, sin importarle el sufrimiento que causaba a los árboles dañados, como a la propia naturaleza circundante, y mucho menos sin tomar en consideración lo que los Dioses le habían indicado. Por el contrario, el póto si respetó lo que se le había solicitado, llevando a cabo un cuido y protección ambiental, que el malecu no dejó de reconocerle, y que de algún modo se lamenta por no haber hecho lo mismo. Por lo que este aspecto positivo parecía tener por intención de encaminar nuevamente al malecu a una práctica conservacionista de la cual hacía tiempo (indefinido) se había apartado, y recriminarle que el póto, a pesar de ser "tontito", no cometía el mismo agravio21.

21 Como se indicó, en la trama de la plática se remite al malecu antiguo, y por ende a otro tiempo narrativo al hacer del póto el protagonista de texto VIII. Como parte de su acervo cultural, este otro tiempo narrativo apela a su cosmovisión (ver Laca Majifijica), la cual se cimienta sobre un equilibrio y contacto en la naturaleza, en la que los elementos naturales y el ser humano se relacionan como un todo. Por ello, el contexto de la plática es comprensible: el malecu estaba maltratando la naturaleza, y por tanto, actuando contra los valores del endogrupo. No obstante, la evocación de un recuerdo en el que el póto si obedece y el malecu no, propició que el narrador abandonase momentáneamente la narración e introdujese elementos más cercanos al malecu "actual", cuando puntualiza en las líneas 10-11 del texto VIII que los malecus no obedecen, cortando todo tipo de árbol. Estas líneas son un intertexto que introduce un pesar "más cercano" para las generaciones contemporáneas del endogrupo, causado por -lo que Sánchez-Avendaño (2015, p.98-117) denomina- el "segundo contacto intenso" con la cultura no-indígena (principalmente costarricense vallecentralista y nicaragüense circundante de la frontera); por lo que en VIII, 10-11 se crea por un breve momento un vínculo entre un recuerdo de la cultura malecu antigua con un pesar más actual. Básicamente Sánchez-Avendaño (2015, p.98-117) expone que, a partir de la segunda mitad del siglo XX, el malecu fue inmerso nuevamente en un proceso sistemático de desposeimiento de tierra. El primer momento de contacto intenso fue con el casi exterminio total por parte de los huleros nicaragüenses (1868-1889) que invadieron su territorio, matando a unos y vendiendo como esclavos a otros en Nicaragua, y violando mujeres, lo que dio paso a que no solamente su territorio se viese reducido, sino también a la colonización de parte familias nicaragüenses, como también costarricenses y estadounidenses (Sánchez-Avendaño, 2015, p.95). En el segundo contacto intenso, se dieron casos de agresiones físicas y amenazas de parte de los no-indígenas para despojarlos de la tierra, como también de otros medios deshonestos como el canje de tierra por rifles o perros, o bien del engaño en que se apropiaban de más tierra de la que se había acordado comprar (Sánchez-Avendaño, 2015, p.99). Una vez con la tierra, los no-indígenas "limpiaban" el terreno, es decir, deforestaban en orden a utilizarla para cultivo y ganadería. Estos hechos, se podrían interpretar en que el malecu que perdía la tierra, de algún modo, se hacía responsable de la muerte de los árboles que narra el texto VIII, y que algunos de ellos sucumbían a los nuevos valores económico-agrarios del mercado conducentes a la destrucción de la naturaleza.

Parece que el recuerdo del póto protegiendo y cuidando los árboles, el cual tenía por finalidad generar un aliciente moral respecto a una ética ambiental, fue un detonante en el narrador para que externara brevemente, en dos líneas, su malestar, generando de esa manera un intertexto en el que se asoma rápidamente las secuelas del segundo contacto intenso que condujo a fallar en el cumplimiento de las órdenes ambientales dadas por Nharíne. Considerando este intertexto desde el siglo XXI, se puede afirmar que dicho aliciente moral concebido en la filosofía malecu antigua, continúa teniendo su vigencia en épocas más cercanas; y que muy posiblemente este estímulo haya aumentado el sentido de culpa, debido a que el malecu contemporáneo al haber visto en la figura de su póto estereotipado, que este y con todas sus deficiencias, no sucumbió al irrespeto del ambiente, mientras que los malecus tanto antiguos como los antepasados más cercanos al tiempo actual, siendo superiores a esos "tontuelos", debieron en ambas ocasiones mantenerse fuertes a pesar de las circunstancias. Es decir, si los "tontos” pótos obedecieron a Nharíne, también los malecus debieron obedecer, pero fallaron dos veces. 
Por consiguiente, de manera general el malecu observaba que el póto tenía un buen comportamiento, ya que no se conducía mal (I, 30; IV, p.138; VII, p.149), lo cual brindaba alicientes morales para el actuar del endogrupo, a pesar de sus deficiencias mentales, su inestabilidad emocional, su "medio" vaga conducta laboral y su "tremendosidad" sexual. Algunos de estos estímulos fueron reconocidos aunque no practicados, evidenciando aspectos identitarios que el malecu negaba de sí, pero que estaban presentes en su manera de ser; mientras que otros sirvieron para reforzar actuares ya existentes, o tratar de corregir conductas en las que flaqueaban o que se habían abandonado.

Finalmente, podría decirse que el máximo aliciente moral consistía en recordar y exhortar a los malecus que sus actos tienen consecuencias, debido a que el póto, con todo y sus fallos laborales y sexuales, por seguir las órdenes de los Dioses, obtuvieron una buena muerte ${ }^{22}$, por cuanto que no fueron víctimas del cataclismo ${ }^{23}$. Incluso se ganaron el aprecio de los Dioses, quienes los defendieron de las atrocidades a que los sometían los ogros, matando y exiliando a estos últimos fuera del territorio póto antes del cataclismo (ver Pláticas sobre ogros). Solamente aquellos pótos que se condujeron inadecuadamente, merecieron una mala muerte antes de la transformación de la tierra: "pocos de ellos morirán como macharos,/ pocos de ellos... e e... se ahogarán,/ a pocos de ellos los matará la serpiente,/ a pocos de ellos los matará... devorará el tigre" (II, 52-55). Por lo que un buen comportamiento implica, desde la filosofía malecu antigua, ganarse una buena muerte, que en su sistema de creencias religiosas significa que al morir se irá a morar con los Dioses. Precisamente esto fue lo que obtuvieron la mayoría de los pótos, y de ahí la importancia de utilizar su figura estereotipada como un aliciente.

22 La buena muerte consiste en morir a causa de alguna enfermedad o de manera natural, lo que conduce a que en la vida post-mortem pase a morar en las casas de los tocú maráma, que se encuentran en el mundo físico, concretamente en las cabeceras de los ríos. Por su parte, la mala muerte consiste en que si alguien se comportó inadecuadamente en vida, cuando muera pasa a la vida post-mortem a sufrir castigos con los diablos (maica maráma). Hay un diablo llamado Oronhacafá que habita en el cielo, por lo que el cielo tiene una connotación de tormento, a diferencia del paraíso cristiano. Aquí van aquellos malportados que murieron a causa de una mordedura de serpiente. Otros diablos, por su parte, viven en una parte terrenal del mundo físico, gobernados por Lhára o Jára; a este lugar van los malportados que murieron de manera trágica, excluyendo la mordedura de serpiente.

23 De acuerdo al texto I, 77-78, se dice que todos murieron, especificando que la causa de muerte fue una diarrea, mientras que los textos VI (p.143) y VII (p.148 y 149) no precisan ninguna causa. Por su parte, el texto III, tampoco indica la causa de muerte, pero añade una variante, a saber, que no todos los pótos murieron con el cataclismo: "Sin embargo... se terminaron los botos,/ murieron./ Excepto unos cuántos, en efecto, actualmente están desaparecidos,/ quién sabe adónde se fueron” (III, 79-83). Esto resulta interesante e intrigante, dado que no se explica desde las propias pláticas por qué algunos pótos quedaron vivos después de cataclismo, si precisamente por su buen comportamiento les fue dada una buena muerte. Curiosamente, el texto III tiene un pequeño referente en el texto VII del Laca Majifijica, puntualmente en la línea 1133 en la que se menciona que los póto maráma -entremetidos en una lista en la que aparecen antes y después de ellos los nombres de antiguos linajes malecus- salieron de la cueva Arefé después que Nharíne transformó la tierra. Por tanto, el relato cosmogónico incluye, sin dar mayor explicación, que se crearon nuevamente los pótos (o quizás algunos de ellos), lo que pudo haber dado pie a interpretar que los pótos del texto III son los sobrevivientes del cataclismo. Asimismo, llama la atención que se comente la "actualidad" de su desaparición, y la incógnita del paradero permanezca como un asunto presente, cuando se supone en otros textos que ya todos murieron.

Concerniente a lo anterior, cabe transcribir el comentario de Ibarra-Rojas sobre estas variantes: "Tales observaciones no dejan de sorprender, porque, históricamente, los indios botos se vieron muy poco después de la conquista. Efectivamente, después de principios y mediados del siglo XVI, no aparecen en las fuentes documentales sino hasta aproximadamente en 1640, y luego en 1742, como citáramos antes. En el siglo XVII se reportan cerca del río Sarapiquí, y en el siglo XVIII en el caribe de Nicaragua” (en Constenla-Umaña e Ibarra-Rojas, 2014, p.16o).

A manera de especulación, se podría pensar que la intervención de los Dioses, y particularmente de Nharíne, fue la manera en que los malecus llenaron un vacío histórico sobre cuál fue el devenir de sus congéneres humanos. Las pláticas no permiten corroborar que los malecus tuvieran un conocimiento pleno de los impactos que estaba teniendo la conquista en el decrecimiento poblacional de los pótos, o la servidumbre a la cual estaban sometidos por los huetares y la amenaza, simultánea, de los nicaraos en el siglo XVI (Ibarra-Rojas, 2011), ni mucho menos la posterior migración hacia el río Sarapiquí y al Caribe nicaragüense, a razón de sobrevivencia. No obstante, por ser pueblos vecinos es plausible suponer que tenían algún conocimiento sobre lo que le estaba ocurriendo a los pótos, por lo menos de los sucesos en el siglo XVI y unas décadas más de siglo XVII (cf. Ibarra-Rojas, 2011, p.15); por lo que desde este breve recuento histórico, el texto III parece presuponer un recuerdo de un conocimiento -muy impreciso y difuso, y que en todo caso se perdió- sobre estos eventos históricos, ya que el afirmar que están perdidos y que no se sabe adónde se fueron, de algún modo cuestiona la explicación de la narración de la muerte divina pre-cataclistica, y abre el portillo para considerar que generaciones previas supieron otra versión de los hechos. De todos modos, al ser un recuerdo vago y, básicamente, carente de sustancialidad histórica (para el endogrupo), la narración que se dieron a sí mismos cobró más fuerza, aunque no deja de asombrar que se perpetuara tal recuerdo en el texto III, y en la lapidaria mención del texto VII del Laca Majifijica. 


\section{Conclusión}

Se puede observar que la visión estereotipada del póto cumplía una importante función en la conformación de la identidad del malecu antiguo, y a su vez, servía como aliciente moral. En primer lugar, los estereotipos "facilitan la identidad social, la conciencia de pertenecer a un grupo social” (González-Gabaldón, 1999, p.81), ya que permiten conformar al otro, bajo unos supuestos atributos -en los cuales hay un consenso básico, y por lo menos tácito- que sirven como un "anti reflejo" para que el endogrupo se defina a sí mismo en contraposición suya. El malecu antiguo, al estereotipar al póto, se creaba un marco referencial de pertenencia grupal, en el tanto que solamente podían describirse y adscribirse como tales aquellos seres que no tuvieran las características del exogrupo. En lo que respecta a la descripción identitaria, la autoimagen del malecu dependía de aquellos rasgos que no hubiesen sido adjudicados al póto; por ello la constancia en las narraciones de resaltar por lo menos los cinco grandes estereotipos. Con la adscripción sucedía algo interesante: los malecus reconocían que habían ciertas características positivas en los pótos (como el de cuidar y proteger los árboles, o no ser tan "feíllos"), pero que eran menoscabadas por tratarse de congéneres inferiores, básicamente "tontos". Los malecus no permitieron que los pótos pudiesen adscribirse como malecus, dado que flaqueaban en las demás características; por lo que la adscripción al endogrupo se convirtió en cumplir con rasgos que básicamente se adquirían con el nacimiento. Esto implica que la identidad que se configuraba desde la noción peyorativa del póto, fuese concebida por el malecu antiguo como una cuestión esencialista. Nótese que lo relevante en las pláticas no consiste en proporcionar detalles individuales de cada malecu o póto -aunque se mencionaban algunas excepciones-, debido a que las diferencias intergrupales no estaban en cuestión, sino que la identidad grupal (o social) se refiere "en lo que comparte con su propio grupo y en lo que la diferencia de otros grupos” (Sánchez-Avendaño, 2015, p.21).

En relación con lo anterior, Sánchez-Avendaño comenta -reseñando en lo que consiste el enfoque constructivista de la identidad- que "las identidades proporcionan los recursos para moldear las subjetividades y las experiencias de cada sujeto" (2015, p.16). La visión estereotipada del póto no es una excepción, dado que proveyó alicientes morales que eran de capital importancia para el malecu antiguo, porque mostraba que debía existir una correspondencia entre lo que el malecu decía ser y lo que realizaba o no realizaba, ya que sus acciones denotarían o cuestionarían su identidad. De ahí la insistencia de que no realizase aquellos actos que los pótos ejecutaban, porque solamente ellos por ser atolondrados los cometían, lo que no era admisible para un ser que se veía a sí mismo como superior a su congénere; o bien, que si el póto, siendo "menso", realizaba ciertos actos loables, con mayor razón debía hacerlo un malecu. Por consiguiente, el estereotipo sobre los pótos fue significativo para configurar la identidad y promover alicientes morales, y a su vez sirvió para reforzar una relación bidireccional entre identidad y aliciente moral: la identidad del malecu antiguo surgió en contraposición de los estereotipos con que caracterizaron a sus vecinos, implicando que habían actuaciones que eran propias para cada grupo; mientras que el cumplimiento o falta a los estímulos morales, que surgían de la figura prejuiciada del póto, facilitaba precisar si había o no una correspondencia entre lo que se hacía y lo que se expresaba ser.

\section{Referencia bibliográfica}

Cano-Gestoso, José Ignacio. (1993). Los estereotipos sociales: el proceso de perpetuación a través de la memoria selectiva. Madrid: Editorial de la Universidad Complutense de Madrid.

Casal-Madibeitia, Sonia. (2005-6). "Los estereotipos y los prejuicios: cambios de actitud”. Estudios de Lingüística Inglesa Aplicada, 6, p.135-149.

Castillo, R. (2005a). "El territorio histórico maleku de Costa Rica”. Revista Reflexiones, 84 (1), p.71-85.

Castillo, R. (2005b). "Población indígena maleku en Costa Rica”. Anuario de Estudios Centroamericanos, 31, p.115-136. 
Constenla-Umaña, Adolfo. (1992). "Hagiografía y Antihagiografía en la tradición oral guatusa”. Filología y Lingüística, XVIII, 1, p.83-124.

Constenla-Umaña, Adolfo (1993). Laca Majifijica. La Transformación de la Tierra. (Introducción, transcripción y traducción de Adolfo ConstenlaUmaña; narración por Eustaquio Castro y Antonio Blanco). San José: EUCR.

Constenla-Umaña, Adolfo. (1996). Poesía tradicional indígena costarricense. (Serie antológica). San José: EUCR.

Constenla-Umaña, Adolfo. (2011a). Pláticas sobre felinos. (Narración de Eustaquio Castro; introducción, transcripción y traducción de Adolfo ConstenlaUmaña). San José: EUCR.

Constenla-Umaña, Adolfo. (2014). Pláticas sobre ogros. (Narración y colaboración en la transcripción y traducción de Eustaquio Castro; introducción, transcripción y traducción de Adolfo ConstenlaUmaña). San José: EUCR.

Constenla-Umaña, Adolfo; e Ibarra-Rojas, Eugenia (2014). "Anotaciones etnohistóricas sobre los indígenas botos: confluencia de datos históricos, antropológicos y de la tradición oral malecu". Estudios de Lingüística Chibcha, 33, p. 111-164. [Este artículo contiene las 'Pláticas de bótos', en su versión malecu y española]

Eco, Umberto; y De Michele, Girolamo. (2010). Historia de la belleza. Barcelona: Debolsillo.

Galante-Marcos, Elena (directora). (sin año, A): Malecu Usirraca Marama. Libro de Leyendas Malecu. Proyecto Rio Frío. (Carece de editorial e imprenta, y de lugar)

González-Gabaldón, Blanca. (1999). "Los estereotipos como factor de socialización en el género". Comunicar, 12, p. 79-88.
Guevara-Berger, Marcos; y Chacón-Castro, Rubén. (1992). Territorios indios en Costa Rica: orígenes, situación actual y perspectivas. San José: García Hermanos.

Guevara-Víquez, F. (2011). Cronología básica de los pueblos indígenas de Costa Rica: desde los inicios del siglo XVI hasta el año 200o. San José: Siwá Pákö [Comisión integrada por MEP (Ministerio de Educación Pública) - UCR (Universidad de Costa Rica) - UNA (Universidad Nacional de Costa Rica) - UNED (Universidad Estatal a Distancia)]

Ibarra-Rojas, Eugenia. (2011). "Los nicaraos, los indios votos y los huetares en escenarios conflictivos en el siglo XVI". Cuadernos de Antropología, No. 21, p.1-23.

Instituto Nacional de Estadística y Censos (INEC) (Costa Rica) (2013). X Censo Nacional de Población y VI de Vivencia 2011. Territorios indígenas: principales indicadores demográficos y socioeconómicos. San José: INEC.

Junta de Educación Palenque Margarita (J.E.P. Margarita) Instituto de Estudios de las Tradiciones Sagradas de Abia Yala (IETSAY). (2000). Narraciones malekus. San José: Tikal.

Mejía-Marín, Noemy. (1994). Historias malecus. (Narración y traducción de Noemy Mejía-Marín; introducción y recopilación de Raúl Bolaños Arce, Juan de Dios Ramírez Gatgens, y Rocío Alvarado Cruz). Heredia: EUNA.

Naciones Unidas (2013). Declaración y Programa de Acción de Viena. 20 años trabajando por tus derechos. 1993: Conferencia mundial de derechos humanos. Oficina del Alto Comisionado de las Naciones Unidas para los Derechos Humanos.

Quintana-Monge, Lorena (2016). Enfoques y críticas del concepto de identidad. PODIUM, No. 29, p. 43-6o 
Sánchez-Avendaño, Carlos. (2015). La cola de la iguana. El pueblo malecu ante el desplazamiento de su lengua y su cultura tradicional. San José: EUCR.

Sánchez-Avendaño, Carlos. (2011). "Caracterización cualitativa de la situación sociolingüística del pueblo malecu". Estudios de Lingüística Chibcha, 30, p. 63-90.

Sen, Amartya (2007). Identidad y Violencia. La Ilusión del Destino. Buenos Aires: Katz.

Solano-Fallas, A. (2019a). "Los felinos dijeron “QQué haremos?”. Sobre la elección en la filosofía antigua malecu". Cátedra, 16, p.39-55.

Solano-Fallas, A. (2019b). "Ogros y tarocafárrafas en los malecus: identidad y aliciente moral”. Revista Pensamiento Actual, Vol. 19, No. 33, p.1-14.

Solano-Fallas, A. (2018). "Ogros en los malecus: sobre la elección y la responsabilidad en la filosofía antigua malecu”. Revista humanidades, Vol. 8, No. 2, p.1-29.

Solano-Fallas, Andrés. (2016). "El bien y el mal, la elección, y la muerte en la cosmogonía malecu "Laca Majifijica"/ The Good and Evil, the Chossing and the Death in the Cosmogony Malecu "Laca Majifijica””. Revista Pensamiento Actual, Vol. 16, No. 26, p.25-32.

\section{Literatura consultada}

Bolaños-Esquivel, Bernardo; y González-Campos, Guillermo. (2010). Las miradas con que vemos. Análisis de la representación audiovisual de los pueblos indígenas de Costa Rica. San José: Vicerrectoría de Acción Social, Universidad de Costa Rica.

Constenla-Umaña, Adolfo. (2011b). "La diversidad lingüística de Costa Rica: las lenguas indígenas". Revista de Filología y Lingüística, 37, 2, p.93-106.

Echánove-Trujillo, Carlos. (1976). Diccionario de sociología. México: Jus.

Espinoza-Romero, Elvia; Mejía-Marín, Noemy; y OvaresBarquero, Sandra. (2011). "El Malecu: Una cultura en peligro de extinción. Maleku: A culture in Danger of Extintion.”. Revista Electrónica Educare. Vol. XV, No Extraordinario, p.69-84.

Fundación Coordinación de Pastoral Aborígen (FUNCOOPA)-Instituto de Estudios de las Tradiciones Sagradas de Abia Yala (IETSAY). (1999): Pueblos indígenas de Costa Rica: historia y situación actual. San José: Tikal.

Galante-Marcos, Elena (directora). (sin año, B): Diccionario Malecu. Proyecto Rio Frío. (Carece de editorial e imprenta, y de lugar)

Ibarra-Rojas, Eugenia. (2003). Las sociedades cacicales de Costa Rica (Siglo XVI). San José: EUCR.

Kottak, Conrad Phillip. (2006). Antropología cultural. Madrid: McGraw-Hill.

Maalouf, Amin. (2002). Identidades Asesinas. Madrid: Alianza.

Margery-Peña, Enrique. (2007). Estudios de mitología comparada indoamericana. Tomo II. El origen del fuego y concepciones sobre el lugar de los muertos en pueblos indoamericanos. San José: EUCR. 
Quesada-Pacheco, Miguel Ángel. (2012). Nuevo diccionario de costarriqueñismos. Cartago: Editorial Tecnológica de Costa Rica.

Rodríguez, Jorge Mario. (2010). Derechos humanos: una aproximación ética. Ciudad de Guatemala: F\&G Editores.

Salazar-Salvatierra, Rodrigo. (2006). El indígena costarricense: una visión etnográfica. The Costa Rican indigenous people: an ethnographic overview. Cartago: Editorial Tecnológica de Costa Rica.

Sánchez-Avendaño, Carlos. (2013). “Apropiación por parte de los miembros del pueblo malecu de la ortografía práctica de su lengua”. Estudios de Lingüística Chibcha, 32, p. 209-229.

Solano-Fallas, Andrés; y Herrera-Valenciano, Minor. (2017). "Felinos en los malecus: simbolización de la muerte como aliciente moral". Revista de Filosofía de la Universidad de Costa Rica, Vol. LVI, No. 144, p.171178.

Solano-Salazar, Elizabeth: "La población indígena en Costa Rica según el censo 2000” en Rosero Bixby, Luis (ed.). (2004). Costa Rica a la luz del censo del 2000. San José: Centro Centroamericano de Población de la Universidad de Costa Rica.

Tenorio-Alfaro, Luis. (1990). Reservas indígenas de Costa Rica. San José: Imprenta Nacional.

Theodorson, George; y Theordorson, Achilles. (1978). Diccionario de sociología. Buenos Aires: Paidós.

Zavala, Magada; y Araya, Seidy. (2008). Literaturas indígenas de Centroamérica (Segunda edición revisada). Heredia: EUNA. 